\title{
Screening of Derris indica Bennet. for cytotoxicity against Artemia salina and phytotoxicity on mustard seeds
}

\author{
Omar Ali Mondal ${ }^{1}$, K. A. M. S. H. Mondal ${ }^{1}$, Nurul Islam ${ }^{2}$ and Ataur Rahman Khan ${ }^{2}$ \\ ${ }^{1}$ Institute of Biological Sciences, University of Rajshahi, Rajshahi-6205, Bangladesh. ${ }^{2}$ Department of Zoology, \\ University of Rajshahi , Rajshahi-6205, Bangladesh.
}

\begin{abstract}
Chloroform extracts of the fruit shell, leaves, root bark, root wood, seeds, stem bark and stem wood of Derris indica Bennet. were tested against the brine shrimp, Artemia salina nauplii. All the test extracts of $D$. indica were found to be effective. The $L C_{50}$ values of the extracts were $15312.37,92.074$ and 29.661 ppm for the fruit shell; 60922.83, 61.522 and 23.777 ppm for the leaf; 15312.37, 51.477 and 19.169 ppm for the root bark; $2598.584,30.480$ and 8.260 ppm for the root wood; $545.025,26.730$ and 7.719 ppm for the seed; $60922.83,114.549$ and $29.572 \mathrm{ppm}$ for the stem bark and $7734.618,58.501$ and $23.694 \mathrm{ppm}$ for the stem wood at 30 minute, 24 hours and 48 hours post exposures respectively at doses 200, 100, 50, $25,12.5,6.25,3.125$ and $1.563 \mathrm{ppm}$ against $A$. salina. The toxicity of the extracts could be arranged in the order: seed > root wood > root bark> stem wood > leaf > fruit shell > stem bark extract. However, the extracts did not significantly inhibit the germination of mustard oil seeds, and thus its application to crops or to the crop field may not cause any harm to crop plants.
\end{abstract}

Key words: Derris indica, cytotoxicity, Artemia salina nauplii, phytotoxicity, mustard seeds. - Corresponding author: Dr. Md. Ataur Rahman Khan

\section{Introduction}

Natural products derived from plants, as an alternative to conventional insecticides for insect control, is now-adays very popular among the IPM practitioners. Plantderived pesticides are more readily biodegradable; therefore they are less likely to contaminate the environment. Moreover, the botanical pesticides break down readily in soil and are not stored in plant or animal tissues.

Being a medicinal plant, Derris indica Bennet. might contain some antipathogenic properties. Powdered seeds of this plant are valued as febrifuge and tonic, and are used in bronchitis and whooping cough. The seeds are also reported to be used as a fish poison (Kirtikar and Basu, 1935), and the seed oil is used as a soap liniment to treat scabies, herpes and rheumatism (Burkill, 1966). The leaf extract is active against Micrococcus pyogenes var. aureus (Anon, 1969). The leaf juice is prescribed in flatulence dyspepsia, diarrhoea and cough and also considered as a remedy for leprosy and gonorrhoea. The root juice is used for cleansing foul ulcers and sores, and to treat gonorrhoea. Roots are used as fish-poison by the aborigins of Australia (Kirtikar and Basu, 1935). The dried flowers are used as decoction to quench thirst in diabetes. The fresh bark juice is given internally in bleeding piles (haemorrhoids) and a decoction of bark is used against beri-beri (Anon, 1969). Cheema et al. (2003) have advocated the commercial utilization of sorghum water extracts for weed management in wheat. Ethanol extracts of $D$. trifoliata showed different mortality rates of brine shrimp which increased proportionally with the increasing concentrations of the extracts (Saifullah and Azam, 2011). Daruliza et al. (2012) traced the anti-Candida activity and brine shrimp toxicity assay of Ganoderma boninense. The insecticidal activity of this plant against Callosobruchus maculatus has been determined (Mondal and Islam, 2008), and antibacterial and larvicidal potentials have also been worked out (Mondal et al., 2010). Germination characteristics of Maize seeds under different ageing treatment have been done by Siadat et al., (2012). Another seed germination test was conducted by Geetha et al., (2011). Seed priming is known as technique of seed enhancement that improves germination or seedling growth in many crops such as Dry bean (Phaseolus vulgaris L.), cordia (Cordia millennii) (Adebisi, 2011), coffee (Coffea arabica L.) (Gebreselassie et al., 2010), capsicum (Capsicum annum) and Agropyron elongatum (Tavili et al., 2010)

Various workers investigated $D$. indica giving emphasis mostly on the chemical constituents and their medicinal profile but very few works have been done on its pesticidal importance. In this investigation, cytotoxic and phytotoxic activity tests of $D$. indica were carried out on the brine shrimp, Artemia salina nauplii and the musatard seeds respectively to evaluate the efficacy of the plant parts as a possible source of potential secondary metabolites to be used as environment friendly pest control agents.

\section{Materials and Methods}

Preparation of plant materials for extraction: The fresh leaves, fruit shell, root bark, root wood, seeds, stem bark, and stem wood of $D$. indica were collected from the campus of the University of Rajshahi, Bangladesh. After drying under shade the plant materials were powdered in a grinder machine.

Chemical extraction of the collected materials: Chloroform was selected as a solvent to extract seven different parts of $D$. indica separately. The ground dried materials, viz. leaves, fruit shell, root bark, root wood, seeds, stem bark, and stem-wood were extracted with sufficient amounts of chloroform $(500 \mathrm{~g} \times 1500 \mathrm{ml} \times 3$ times) for each of the items. Separate extracts were collected by the cool method after 72 hours of plunging for each of the plant parts. Extracts were subjected to 
filtration and evaporation of the solvent. The residues were kept in a refrigerator after proper labeling.

Since the lethality test involves the culture of brine shrimp nauplii, i.e., the nauplii should be grown in water with salinity similar to that of sea water, while the seawater contains $3.8 \%$ sodium chloride. Accordingly, a $3.8 \%$ sodium chloride solution was prepared by dissolving 38 $\mathrm{gm}$ sodium chloride in $1000 \mathrm{ml}$ distilled water. The $\mathrm{P}^{\mathrm{H}}$ of the brine water thus prepared was maintained between 8 and 9 using $\mathrm{NaHCO}_{3}$.

Brine water was taken in a small tank and shrimp eggs $(1.5 \mathrm{gm} / \mathrm{L})$ were added to one side of the perforated tank with a constant oxygen supply. A constant temperature $\left(37^{\circ} \mathrm{C}\right)$ and sufficient light were maintained. After 48 hours, shrimp nauplii were collected and used for the experiment. For the seed germination test, fresh and healthy mustard seeds were collected from the market.

\section{Cytotoxicity test:}

Preparation and application of doses on $A$. salina

Chloroform extracts of the $D$. indica samples were applied against the brine shrimp nauplii. For the fruit shell, leaves, root bark, root wood, stem bark and stem wood samples $4 \mathrm{mg}$ were initially dissolved in $200 \mu \mathrm{l}$ of pure dimethylsulfoxide (DMSO) to make them hydrophilic before adding $19.98 \mathrm{ml}$ of water to get a concentration of $200 \mathrm{ppm}$ for each of the samples separately which were used as stock solutions for all the extracts and from these concentrations other successive doses were prepared separately for each of the extracts through the serial dilution method. A series of concentrations, e.g. 200, 100, 50, 25, 12.5 and 6.25 ppm were prepared for the extracts separately. However, for the seed extract $2 \mathrm{mg}$ was initially dissolved in $100 \mu \mathrm{l}$ of DMSO to make it hydrophilic before adding $19.98 \mathrm{ml}$ of water to get a concentration of $100 \mathrm{ppm}$ which was used as the stock solution for the seed extract. The following concentrations were made from the stock solution: $100,50,25,12.5,6.25,3.125$ and $1.563 \mathrm{ppm}$.

Brine shrimp eggs were hatched in simulated seawater to get nauplii. Test samples were prepared by the addition of the requisite amounts of DMSO for obtaining desired concentrations of the test sample. The nauplii were counted by visual inspection and were taken in vials containing $5 \mathrm{ml}$ of brine water. Then samples of different concentrations were added to the pre-marked vials with the help of a micropipette. The vials were left for 24 hours and then the nauplii were counted again to find out the cytotoxicity of the test agents and compared to the results with positive control.

Preparation and application of doses on mustard seeds:

In this experiment 4 doses from the fruit shell, leaves, root bark, root wood, seed, stem bark and stem wood extracts of $D$. indica were made as $1 \mathrm{mg}, 0.75 \mathrm{mg}, 0.50$ $\mathrm{mg}$ and $0.25 \mathrm{mg} / \mathrm{ml}$ freshwater. Because of insolubility of the extract in water it was needed to add $100 \mu \mathrm{l}$ DMSO with the weighed extract before mixing with water.
For application of doses a number of petridishes $60 \mathrm{~mm}$ diam. were used. Filter papers were placed inside the petridishes and doses were applied separately. Five mustard seeds were put in every petridish and three replications were set for each concentration and a control with three replications was also maintained. All the petridishes were kept covered to avoid drying. The humid condition inside the petridishes helped the seeds to germinate. Then the petridishes were placed in a safe place with plenty of light and air. Germination (\%) was carefully recorded at various concentrations of different extracts of $D$. indica.

\section{Collection and analysis of data for cytotoxicity}

The test tubes containing the nauplii with the treated brine water were kept on a rack near the window in the laboratory. The recorded mortality was corrected by the Abbott's (1925) formula:

$P_{r}=\frac{P_{0}-P_{C}}{100-P_{C}} \times 100$

Where,

$\mathrm{P}_{\mathrm{r}}=$ Corrected mortality (\%),

$\mathrm{P}_{\mathrm{o}}=$ Observed mortality (\%), and

$\mathrm{P}_{\mathrm{C}}=$ Control mortality $(\%)$.

Mortality data were subjected to statistical analysis according to Finney (1947) and Busvine (1971) by using software developed at the Department of Agricultural and Environmental Science, University of Newcastleupon -Tyne, U.K. The dose-mortality relationship was expressed as median lethal concentrations $\left(\mathrm{LC}_{50}\right)$.

\section{Results and discussions}

The results of dose-mortality assays of $D$. indica extracts against $A$. salina nauplii are presented in table 1 and illustrated in Fig. 1. Most of the test extracts showed remarkable dose-mortality effects against the 1 day old nauplii of $A$. salina. The degrees of activity of the extracts against the brine shrimp nauplii could be arranged in the order: seed > root wood > root bark $>$ stem wood $>$ leaf $>$ fruit shell $>$ stem bark extract.

In general, the application of the chloroform extracts of different parts of $D$. indica on the germination of mustard seeds produced significant effects (Table 2 ).

The ethanolic extracts of $D$. scandens (Roxb.) Benth, along with other test extracts showed cytotoxicity $\left(\mathrm{LC}_{50}<30 \mu \mathrm{g} / \mathrm{ml}\right)$ against lung and prostate cancer cell lines (Acharya and Thomas, 2007). LC $_{50}$ values of petroleum ether, chloroform and methanol extracts on A. Salina Leach were recorded as $1.14,1.1$, and $54.9 \mathrm{mg} / \mathrm{l}$ respectively. Chemical analysis revealed the presence of fatty acids, steroids, triterpenoids, alkaloids, phenols, and phenyl propanoids, tannin, and mucilage in the extracts (Uyub et al., 2010).

The present results are more or less similar to those of Mondal and Islam (2008). However, the fruit shell and the leaf extracts did not offer any mortality of the test insect (Callosobruchus maculatus) and the intensity of activity could be arranged in a descending order as seed > root wood > root bark > stem wood > stem bark. 
Table1: Cytotoxicity of $D$. indica extracts against $A$. salina nauplii.

\begin{tabular}{|c|c|c|c|c|c|c|}
\hline \multirow{2}{*}{ 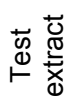 } & \multirow{2}{*}{$\begin{array}{c}\text { Time } \\
\text { exposed }\end{array}$} & \multirow{2}{*}{$\mathrm{LC}_{50}$ value $(\mathrm{ppm})$} & \multicolumn{2}{|c|}{ 95\% Confidence limits } & \multirow{2}{*}{ Regression equation } & \multirow{2}{*}{$x^{2}$ Value(df) } \\
\hline & & & Lower limit & Upper limit & & \\
\hline \multirow{3}{*}{ 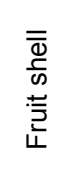 } & $30 \mathrm{~min}$ & 15312.7 & 34.995 & 6700098 & $Y=2.791+0.528 X$ & $0.546(4)$ \\
\hline & $24 \mathrm{~h}$ & 92.074 & 50.777 & 166.959 & $Y=3.182+0.925 X$ & $0.319(4)$ \\
\hline & $48 \mathrm{~h}$ & 29.661 & 20.117 & 43.734 & $Y=3.284+1.166 X$ & $0.994(4)$ \\
\hline \multirow{3}{*}{ 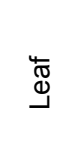 } & $30 \mathrm{~min}$ & 60922.83 & 5.791 & $6.409 \mathrm{e}+08$ & $Y=2.721+0.476 X$ & $0.550(4)$ \\
\hline & $24 \mathrm{~h}$ & 61.522 & 37.700 & 100.397 & $Y=3.259+0.973 X$ & $0.278(4)$ \\
\hline & $48 \mathrm{~h}$ & 23.777 & 16.546 & 34.168 & $Y=3.194+1.312 X$ & $0.911(4)$ \\
\hline \multirow{3}{*}{ 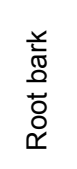 } & $30 \min$ & 15312.37 & 34.995 & 6700098 & $Y=2.791+0.528 X$ & $0.546(4)$ \\
\hline & $24 \mathrm{~h}$ & 51.477 & 27.505 & 96.342 & $Y=3.766+0.721 X$ & $0.279(4)$ \\
\hline & $48 \mathrm{~h}$ & 19.169 & 11.440 & 32.122 & $Y=3.788+0.945 X$ & $1.225(4)$ \\
\hline \multirow{3}{*}{ 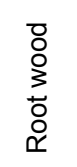 } & $30 \min$ & 2598.584 & 110.001 & 61387.03 & $Y=2.737+0.663 X$ & $0.204(4)$ \\
\hline & $24 \mathrm{~h}$ & 30.480 & 16.123 & 57.620 & $Y=3.989+0.682 X$ & $5.686 \mathrm{e}-02(4)$ \\
\hline & $48 \mathrm{~h}$ & 8.260 & 4.036 & 16.905 & $Y=4.125+0.954 X$ & $2.352(4)$ \\
\hline \multirow{3}{*}{ 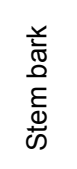 } & $30 \mathrm{~min}$ & 60922.83 & 5.791 & $6.409 \mathrm{e}+08$ & $Y=2.721+0.476 \mathrm{X}$ & $0.550(4)$ \\
\hline & $24 \mathrm{~h}$ & 114.549 & 47.100 & 278.582 & $Y=3.612+0.674 X$ & $0.374(4)$ \\
\hline & $48 \mathrm{~h}$ & 29.572 & 17.862 & 48.960 & $Y=3.712+0.876 X$ & $8.718 e-02(4)$ \\
\hline \multirow{3}{*}{ 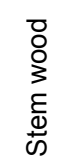 } & $30 \mathrm{~min}$ & 7734.618 & 68.723 & 870519.9 & $Y=2.530+0.635 X$ & $0.389(4)$ \\
\hline & $24 \mathrm{~h}$ & 58.501 & 28.500 & 120.083 & $Y=3.859+0.646 X$ & $0.356(4)$ \\
\hline & $48 \mathrm{~h}$ & 23.694 & 13.599 & 41.286 & $Y=3.867+0.824 X$ & $0.597(4)$ \\
\hline \multirow{3}{*}{$\begin{array}{l}0 \\
\Phi \\
\infty\end{array}$} & $30 \mathrm{~min}$ & 545.025 & 81.267 & 3655.26 & $Y=2.452+0.931 X$ & $0.799(4)$ \\
\hline & $24 \mathrm{~h}$ & 26.730 & 16.271 & 43.912 & $Y 3.678+0.926 X$ & $1.335(4)$ \\
\hline & $48 \mathrm{~h}$ & 7.719 & 4.673 & 12.750 & $Y=4.063+1.056 X$ & $1.568(4)$ \\
\hline
\end{tabular}

Table2. Germination (\%) of Mustard seeds by extracts of different parts of $D$. indica

\begin{tabular}{lc}
\hline $\begin{array}{c}\text { Treatment with following } \\
\text { extratives }\end{array}$ & \begin{tabular}{c} 
Germination \%age \\
\cline { 2 - 2 }
\end{tabular} \\
\hline Fruit shell & Mustard seed \\
Leaf & 90 \\
Root bark & 92 \\
Root wood & 85 \\
Stem bark & 90 \\
Stem wood & 80 \\
Seed & 75 \\
Control & 85 \\
\hline
\end{tabular}

It is important to evaluate the newly found bioactive agents to try against some test crop plants to see whether or not they cause any detrimental effects on target crop(s). Thus, phytotoxicity tests are necessary. Ndakidemi and Dakora (2003) employed legume seed flavonoids and nitrogenous metabolites for an improvement in their understanding of seed chemistry whether they would permit manipulation of these molecules for effective control of pathogens, insect pests, Striga and destructive weeds, as well as for enhanced acquisition of $\mathrm{N}$ and $\mathrm{P}$ via symbioses with soil rhizobia and AM fungi . 


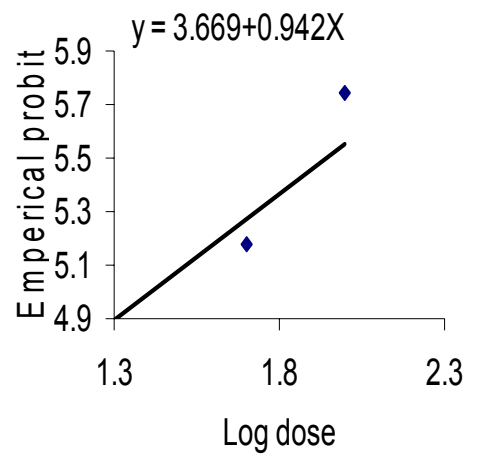

A

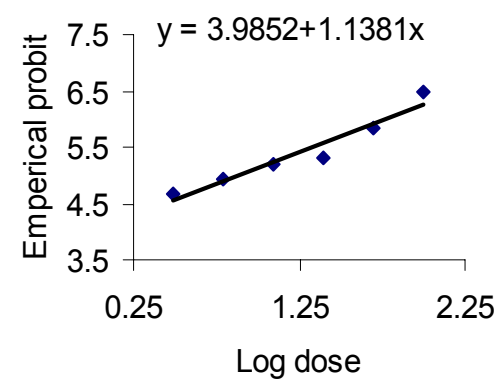

B

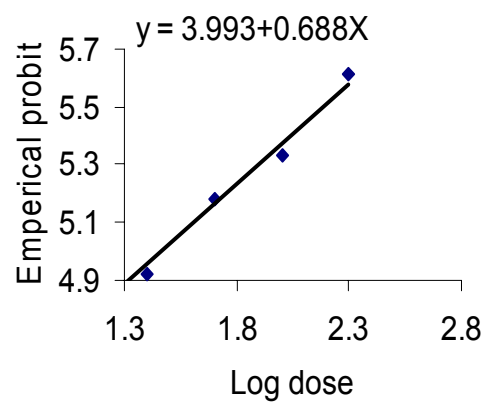

C

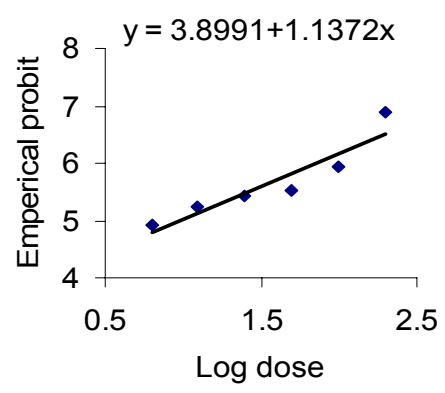

D

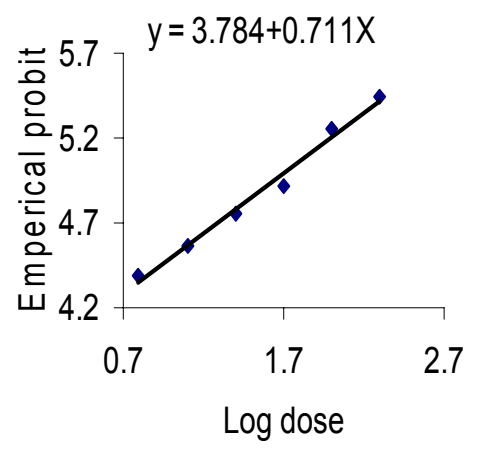

E

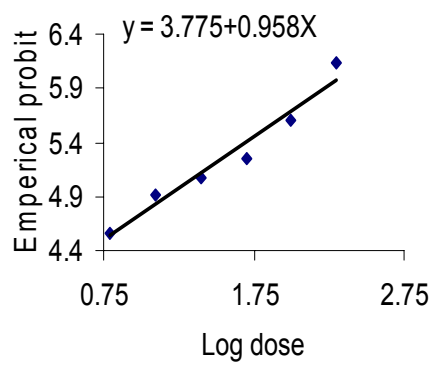

$\mathrm{F}$

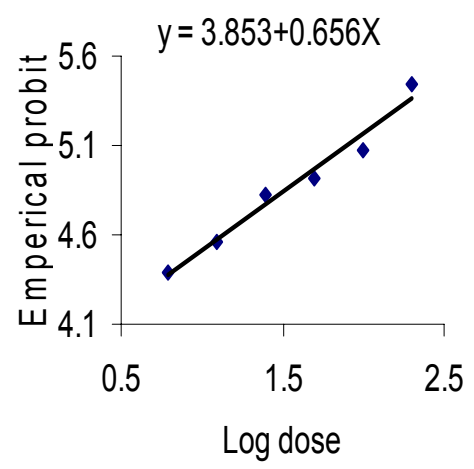

G

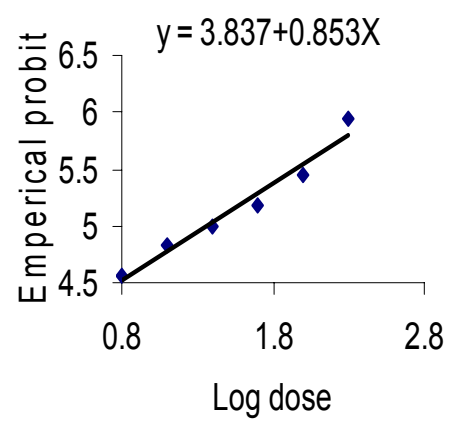

$\mathrm{H}$ 

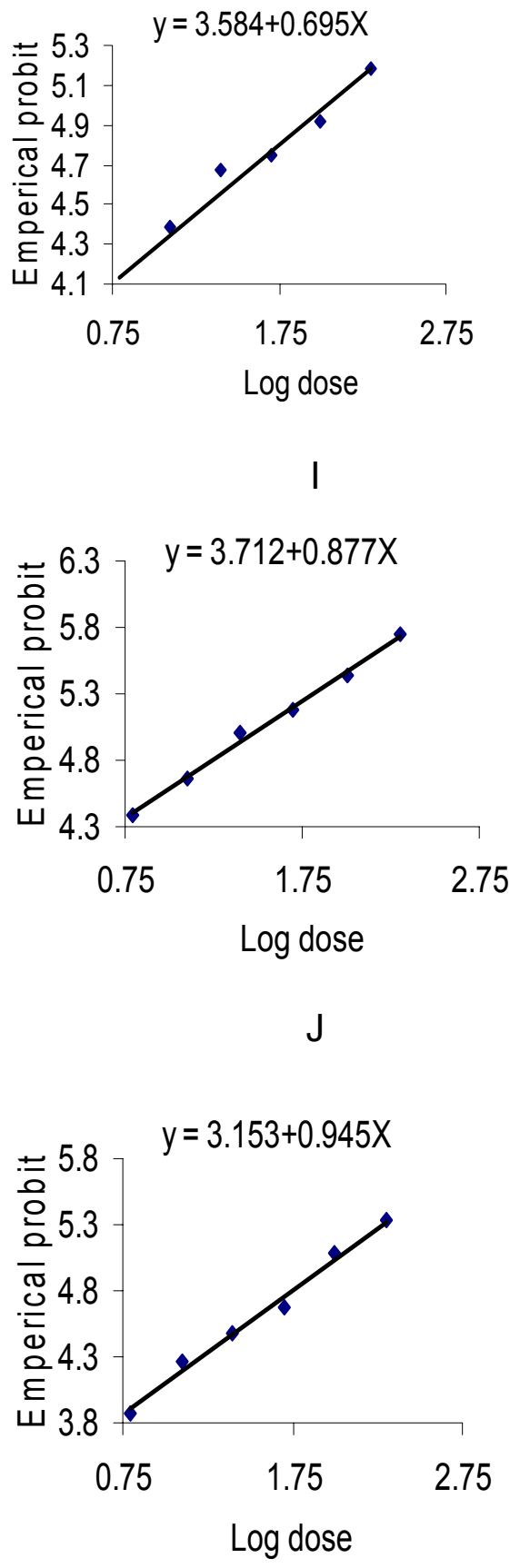

$\mathrm{K}$
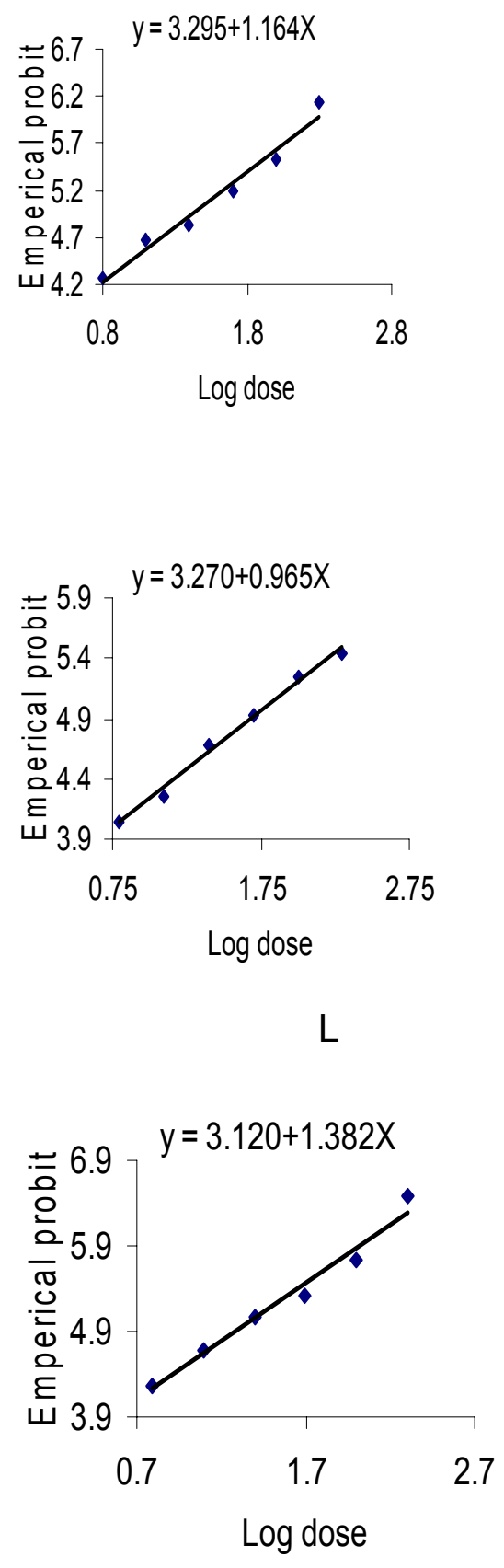

M

Fig. 1. Probit mortality regression lines of the chloroform extracts of $D$. indica: A- Seed/ $24 \mathrm{~h}$; B- Seed/ $48 \mathrm{~h}$; C- root wood/ $24 \mathrm{~h}$; Droot wood/ $48 \mathrm{~h}$; E- root bark/ $24 \mathrm{~h}$ and F- root bark/48h;.G- stem wood/ $24 \mathrm{~h} ; \mathrm{H}$ - stem wood/ $48 \mathrm{~h}$; I- Stem bark/ 24 h; JStem bark / 48 h; K- fruit shell/ $24 \mathrm{~h}$ and L- fruit shell / $48 \mathrm{~h}$; M- leaf/ 24and $\mathrm{N}$ - leaf / $48 \mathrm{~h}$ of exposure against $A$. salina

However, it is also important to see whether or not the plant secondary metabolites having insecticidal or biological activity cause any barrier to the sprouting and growth of seedlings. Phlomina and Srivasuki (1996) reported that leaf leachates of 5 multipurpose tree species (Eucalyptus camaldulensis, Acacia nilotica, Derris indica, Cassia siamea and Sesbania grandiflora) had varying degrees of inhibitory and stimulatory effects on germination percentage. Velu et al.(1996) reported that Acacia sp. retard the plant growth and development. Thakur and Bhardwaj (1992) reported that when wheat seeds were exposed to leachates from leaf extracts of Eucalyptus globulus, Populus ciliata, Juglans regia and Robinia pseudoacacia germination was not affected. 
A perusal of the data shows that $D$. indica extracts produced significant mortalities against $A$ salina nauplii. But the extracts had, in general, no significant phytotoxicity against mustard seeds. However, more comprehensive studies are needed in this line.

\section{Acknowledgements}

The authors are very much grateful to the Director, Institute of Biological Sciences, University of Rajshahi, Rajshahi-6205, Bangladesh for laboratory facilities and to Rajshahi University for providing financial support. The first author is grateful to the authority of Durgapur Degree College, Durgapur- Rajshahi for granting him study leave.

\section{References}

Abbott, W.S. 1925. A method of computing the effectiveness of an insecticide. J. econ. Ent. 18:265-267.

Adebisi, M.A., Akintoye, S.O., Kehinde, T.O. \& Adekunle, M.F. 2011. Seed priming for improved seedling emergence and vigour of cordia(Cordia millennii) seed. Res. J. Seed Sci. 4:137-147.

Anon, 1969. The Wealth of India -A Dictionary of Raw Materials and Industrial Products. 8: 206-210.CSIR, New Delhi.

Burkill, J.H. 1966. A Dictionary of Economic Products of the Malay Peninsula. Art Printing Works, Kuala Lumpur, vols.

Busvine, J.R. 1971. A critical review of the techniques for testing insecticides. Commonwealth Agricultural Bureaux, London. $345 \mathrm{pp}$.

Cheema, Z.A., Khaliq, A. \& Mubeen, M. 2003. Response of wheat and winter weeds to foliar application of different plant water extracts of sorghum. Pak. J. Weed Sci. Res. 9: 89-97.

Daruliza, K.M., Fernandez, L., Jegathambigai, R. \& Sasidharan, S. 2012. Anti-Candida activity and brine shrimp toxicity assay of Ganoderma boninense. Eur. Rev. Med. Pharmacol. Sci. 16(1): 43-8.

Finney, D.J. 1947. Probit analysis: a statistical treatment of the sigmoid response curve. Cambridge University Press, London. $333 \mathrm{pp}$.

Geetha, V.V. \& Balamurugan, P. 2011. Organic seed pelleting in Mustard. Res. J. Seed Sci. 4(3):174-180.

Gebreselassie, W., Mohammed, A. \& Netsere, A. 2010. Presowing treatment of coffee (Coffea arabica L.) seeds to enhance emergence and subsequent growth of seedlings. Res. J. Seed Sci. 3:218-226.
Kirtikar, K.R. \& Basu, B.D. 1935. Indian Medicinal Plants, Vol. III 2nd ed. Basu, L.M., Allahabad, India. pp. 1593-2393.

Mondal, O.A. \& Islam, N. 2008. Toxicity of chloroform extracts of Derris indica Bennet. against Callosobruchus maculatus (F.) adults. Univ. J. Zool. Rajshahi Univ.27:95-96.

Mondal, O.A., Haque, M.E. \& Islam, N. 2010. Antibacterial and larvicidal potentials of Derris indica (Lamk.) Bennet. extractives. Univ. J. Zool. Rajshahi Univ. 29: 21-26.

Ndakidemi, P.A., \& Dakora, F.D. 2003. Legume seed flavonoids and nitrogenous metabolites as signals and protectants in early seedling development. Functional Plant Biology 30:729-745.

Phlomina, N.S. \& Srivasuki., K.P. 1996. Allelopathic studies on agro-forestry species: effect of leaf leachates on seed germination of crop plants. Indian J. Forestry 19(1): 45-53.

Mamoon, S. A. \& Azam, G. 2011. Diuretic activity and brine shrimp toxicity of Derris trifoliata Lour. Int. J. Pharm. Life Sci. 2: 1029-1032

Siadat, S.A., Moosavi, A. \& Zadeh, M.S. 2012. Effect of seed priming on antioxidant activity and Germination characteristics of Maize seeds under different ageing treatment. Res. J. Seed Sci. 5(2):51-62.

Surya, N.A. \& Thomas, J.E. 2007. Advances in Medicinal Plant Research. : 287-317.

Tavili, A., Zare, S. \& Enayati, A. 2010. Hydropriming, ascorbic and salicylic acid influence on germination of Agropyron elongatum Host. seeds under salt stress. Res. J. Seed Sci. 3: 249-255.

Thakur, V.C. \& Bhardwaj, S.D. 1992. Allelopathic effect of tree leaf extracts on germination of wheat and maize. Seed Res. 20(2): 153-154.

Uyub, A.M., Nwachukwu, I.N., Azlan, A.A. \& Fariza, S.S. 2010 In vitro antibacterial activity and cytotoxicity of selected medicinal plant extracts from Penang Island, Malaysia on metronidazole-resistant Helicobacter pylori and some pathogenic bacteria. Ethnobot. Res. Appl. 8: 95-106.

Velu, G., Srinivasan, P.S., Ali, A.M. \& Narwal, S.S.. 1996. Phytotoxic effect of tree crops on germination and radical extension of legumes. Allelopathy: field observations and methodology. Proc. Int. Conf. Allelopathy 1: 299-302. 